\title{
Los temores de Texas a la reconquista mexicana (1836-1845)
}

In busca de una "impresión directa", en el presente trabajo se alteró el método usualmente utilizado por los historiadores, acudiendo en primera instancia a los documentos, y recurriendo luego a fuentes bibliográficas apropiadas para reforzar 0 , en su caso, corregir los conceptos adquiridos.

Se revisó casi toda la correspondencia intercambiada entre Texas y los Estados Unidos de 1836 a $1845,{ }^{2}$ poco consultada por los historiadores mexicanos. Vale señalar que "las primeras impresiones fueron duras", ${ }^{3}$ y México no salía de ellas, de ninguna manera, bien librado. Se dejaba entrever que durante más de ocho años se habia dedicado a fastidiar la vida de los honestos y desdichados texanos. Pero, con el apoyo de libros generales y de monografías $^{4}$ y de una segunda revisión del material documental, se llegó a otra conclusión: si bien Texas pasó momentos amargos por la determinación mexicana de no reconocer su independencia, cada vez que le convino utilizó como un arma de presión diplomática pendiente sobre los Estados Unidos el argumento de la posible reconquista por México y de sus sufrimientos por la guerra en la frontera.

La deducción, interesante, amerita revisar más fuentes (archivos, periódicos, una bibliografía más amplia) y profundizar el análisis. Por lo pronto, se apuntan los primeros resultados.

La derrota de San Jacinto y la retirada de las tropas mexicanas de Texas hicieron definitiva la pérdida de esta provincia. Pese a ello, durante los años siguientes, México consideró la revolución de independencia texana como una sublevación. Mantuvo con firmeza su derecho a ese territorio. No modificaron su actitud ni el reconocimiento de la autonomía de Texas por los Estados Unidos y luego por las grandes potencias europeas, ni la realidad de que no podía emprender de manera terminante la reconquista.

En efecto, el país carecía de recursos para hacerlo. Su atrasada

' Carlos Bosch Garcia. Historia de las relaciones entre México y los Estados Unidos. 1819-1848. México. Secretaria de Relaciones Exteriores, 1985 (Archivo Histórico Diplomático Mexicano. Serie obras monográficas 3, Cuarta época), p. 25.

- La editada por William R. Manning, Diplomatic correspondence of the United States. Inter-American affairs. 1831-1860. Washington, Carnegie Endowment for International Peace. 1932-1939. 12 vols.

Bosch. op. cit. p. 25.

+ Sobre todo Bosch, idem, T. R. Fehrenbach, Lone star. A History of Texas and the Texans. Nueva York. The MacMillan Company, 1968; Joseph M. Nance, After San Jacinto. The Texas-Mexican Frontier, 1836-1841. Austin, University of Texas, 1963 y Allack and counter-attack. The Texas-Mexican Frontier, 1842, Austin, University of Texas. 1964: David M. Pletcher, The Diplomacy of Annexation, Texas, Oregon, and the Mexican War, Columbia Missouri, University of Columbia, 1975; David J. Weber. The Mevican Frontier, 1821-1846. The American Southwest Under Mixico, Albuquerque. University of New Mexico Press, 1932, (Histories of the American Frontier.) 
economía no daba señales de progresar. La agricultura, sobre todo de cereales, declinaba. La industria no prosperaba debido a la pobreza del consumo, de las técnicas y de los capitales. Como en la época colonial, la plata era el principal producto de exportación, por lo que el desarrollo nacional siguió fincado en la mineria. Empero, ésta enfrentó problemas serios, ocasionados por la anarquía política, la tecnologia anticuada, la escasez y carestia de productos básicos para el beneficio de la plata, etcétera.

Las dificultades en los transportes y las comunicaciones no permitieron la articulación del mercado interno. En cuanto al intercambio con el exterior, el país se limitaba a recibir mercancias de fuera y a pagar por ellas. Con todo, el comercio era la rama más próspera de la economía y la más propicia para la formación de capitales. Vinculaba de forma directa a México con Gran Bretaña, Francia y los Estados Unidos, cuyos representantes, diplomáticos y negociantes, gozaban de creciente influencia y poder.

En este México de economia ruinosa, los siete millones de habitantes (1838) se hallaban profundamente divididos en clases y razas. Una gran masa indígena dedicada sobre todo al cultivo de la tierra, miserable y con poco en común con sus demás compatriotas, constituia la mayoria. La dirigia una minoría criolla, dueña del poder político y económico, rectora de la Iglesia, el ejército y la administración pública, que monopolizaba la propiedad urbana y rural extensa, la producción minera e industrial y el gran comercio. Seguía en influencia un grupo intermedio que comenzaba a manifestarse como un motor de cambios, conformado por criollos y mestizos que compartian lugares inferiores en la burocracia, el ejército y el clero, pequeños propietarios que ejercian el comercio en menor escala, la artesanía, la ensenanza y las profesiones liberales. ${ }^{5}$

Sacudido por revueltas federalistas y centralistas, por constantes golpes de Estado, con un Tesoro vacio, en deuda tanto con los agiotistas nacionales y extranjeros como con el ejército y la burocracia, aislado en el Altiplano central, y con un control remoto sobre sus costas y sus fronteras, el gobierno mexicano de la época casi no podia hacer otra cosa que tratar de solucionar los problemas inmediatos. No es dificil comprender la ausencia de una gran empresa de reconquista de Texas, si se considera que el Estado tuvo que enfrentar también sublevaciones indígenas, incursiones "bárbaras", intentos separatistas de Yucatán y de la República de la Sierra Madre, amén de serios problemas internacionales: una guerra con Francia, las presiones británicas y las crecientes reclamaciones de los Estados Unidos, a las que se añadían su desmedido apetito territorial y su decisión de extender las bendiciones de la democracia en el resto de América y de excluir toda influencia europea en el continente.

Por otro lado, el brazo armado de la República mexicana adolecia de graves deficiencias. Pese a "la apariencia militarista de la época, la deserción y la indisciplina eran los males más graves..."6

\footnotetext{
'Ciro Cardoso (coord.), Mévico en el siglo XIX (1821-1910). Historia económica y de la estructura social. México, Nueva Imagen. 1983 (Serie Historia), p. 54, 235-237.

"Josefina Zoraida Vázquez, "Los primeros tropiezos", en Daniel Cosio Villegas "t al.. Historia general de México. México. El Colegio de México. 1976, 4 vols., vol. 3. p. $54-55$.
} 
Alimentado por una leva forzosa de indios, criminales y vagabundos enviados al campo de batalla sin preparación y con escaso armamento, el ejército era, cada día más, una quimera. Sus cuadros de oficiales. escasos de educación militar, mezclados en las diversas luchas politicas, ociosos (debido a su gran número no todos tenian mando), protegidos por un fuero, se hallaban bastante deteriorados. Es claro que el ejército en su conjunto no tenía capa-. cidad para imponer la soberanía de México. Su acción se redujo a unas cuantas correrías hacia el norte, a escaramuzas fronterizas, a intentos de alianza con las tribus indigenas de la región, en fin, al amago constante.

La independencia enfrentó a Texas a nuevos problemas. En realidad, el nuevo país no estaba preparado para defender su recién adquirida soberania. Asi lo señalaría un enviado de los Estados Unidos a su gobierno, al declarar que "sin ayuda extranjera, su seguridad futura debe depender de la debilidad e imbecibilidad de su enemigo más que de su propia fuerza". 7 En estas condiciones corrió con suerte al no poder México emprender una acción definitiva en su contra.

La entonces conocida como "República de la Estrella Solitaria" no tuvo una existencia fácil. Si bien su población se cuadruplicó (gracias sobre todo a la emigración norteamericana su número pasó de unos 30 mil habitantes en 1836 a alrededor de $125 \mathrm{mil}$ hacia 1845$)^{8}$, su comercio mejoró y el casi inmediato reconocimiento diplomático de Washington la afianzó, los texanos seguian siendo una comunidad de frontera, en la que unos cuantos plantadores exportaban su algodón a cambio de bienes importados, mientras la mayoria practicaba una agricultura de subsistencia y ejercia el trueque. Carecian de moneda, de industria, de vida urbana." Padecieron de inflación, devaluación y un erario vacío. Junto con la constante amenaza mexicana, la falta de reconocimiento de las grandes potencias europeas los hizo depender en forma creciente de su vecino del norte a través del comercio, los préstamos y la especulación de sus tierras. El establecimiento de relaciones diplomáticas con Gran Bretaña y Francia en 1842 fue tardío. No haría más que dar a los defensores de la expansión norteamericana otro motivo para anexarse la joven república.

Cabe subrayar que la mayoria de los angloamericanos residentes en Texas se sentian estrechamente vinculados a los Estados Unidos. No era extraño. Los unian lazos de sangre, además del sentimiento común de que la norteamericana era la nación más importante de la Tierra.

Desde sus comienzos como pais independiente y salvo durante unos meses de armisticio, Texas vivió en situación de guerra con su antigua metrópoli. Sin el reconocimiento mexicano de su autonomia, sin una frontera definida y con un ejército inadecuado y carente de recursos, conformado sobre todo con aventureros estadunidenses y con la milicia que se reunia en los momentos de

Henry S. Morfit a John Forsyth, Velasco, 10 de septiembre de 1826, en Manning. (p). (ill., vol. 12, p. 116.

"Luis G. Zorrilla. Historia de las relaciones entre Mexico y los Estados Unidos de.tmérica. 1800-1958, México. Porrúa. 1965. 2 vols.. vol. 1, p. 129.

Fehrenbach. (op. cil.. p. 247. 
emergencia, el territorio entre el río Nueces (lindero histórico de la provincia texana) y el rio Bravo (límite reclamado por Texas) se convirtió en una "tierra de nadie". Quien la atrevesaba arriesgaba su vida y sus bienes.

Las incursiones de México eran contestadas con incursiones de Texas. Cada acto de hostilidad originaba represalias. Sin embargo, tanto las acciones de México como las de Texas no consiguieron más que llevar a los dos países a un callejón sin salida; ni el uno ni el otro podian vencerse de una manera definitiva; ninguno tampoco admitía la derrota.

En ocasiones, la tensión de guerra padecida por los texanos no era más que producto de rumores o falsas noticias. Eso fue lo que sucedió, por ejemplo, a mediados de 1840, cuando el gobierno convocó a la milicia, alarmado porque al parecer el general Arista habia cruzado el río Bravo y varias tribus indígenas concentraban fuerzas considerables junto al río Brazos. Lo que en realidad sucedia era que Arista perseguia a un grupo de adversarios politicos y que los indiós se estaban reuniendo, como todos los años, para levantar su cosecha de maíz.

El rumor de que México emprendia un gran esfuerzo de guerra implicó, en 1843, al presidente de Texas. Muchos lo acusaron entonces de estar de acuerdo con el gobierno enemigo para convertirse en dictador, tan pronto como la exprovincia mexicana fuese reconquistada.

En su correspondencia diplomática con los Estados Unidos, los texanos se valieron de los sufrimientos que les causaba la guerra fronteriza cada vez que trataban de conseguir la anexión, una mediación con el gobierno mexicano, tropas contra los indios hostiles o protección militar para sus costas y linderos.

De ningún modo obtuvieron lo que buscaban. Eso dependia, en realidad, de las circunstancias en los Estados Unidos. Así, en el verano de 1837, ante el peligro tanto de una guerra con México como de la extensión del área de esclavitud, el gobierno de Martín Van Buren rechazó cortés, pero enérgicamente, la propuesta formal de anexión hecha por Texas. El Departamento de Estado declaró que su país estaba ligado a México por un tratado de amistad y comercio que debia y deseaba respetar, ${ }^{10}$ además de que la Constitución no preveía la unión de un estado independiente. Añadió que no se buscaría una fórmula para superar este obstáculo legal mientras continuase el estado de guerra.

Texas mantuvo su propuesta hasta junio de 1838 . Aunque reconocia la dificultad de la reconquista, no dejó de denunciar a México por no respetar "las leyes de los países civilizados al llevar a cabo una guerra de exterminación salvaje" y por buscar la colaboración de las tribus indígenas para invadir el territorio. De esta manera, sus diplomáticos utilizaron diversos pretextos para impedir la reconquista mexicana y tener cerca tropas norteamericanas que ayudasen a las suyas en caso necesario.

La politica exterior de Texas se modificó entre 1839 y 1841 , en

${ }^{119}$ Forsyth a Memecan Hunt, Washington, 25 de agosto de I837, en Manning, (1). (it.. vol. 12, p. 13.

"Hunt a Forsyth. Washington. 12 de septiembre de 1837, en ibidem. vol. 12. p. 144 . 
buena medida por el ascenso a la presidencia de Mirabeau Buonaparte Lamar, quien quiso primero persuadir y luego obligar a México a reconocer la independencia de Texas y a aceptar como frontera el río Bravo. Era claro que su país no podría.prosperar de otra manera. De modo que al fracasar las gestiones de paz, se acudió a la agresión: a la derrotada expedición de-Santa Fe, que pretendia extender el territorio de Texas hacia el oeste, hasta el océano $\mathrm{Pa}$ cífico, o cuando menos dominar toda la región hasta el río Bravo; a la colaboración con los insurgentes de Yucatán; al bloqueo de los puertos mexicanos del golfo.

Resentida por el rechazo norteamericano, la administración Lamar se opuso a cualquier propuesta de anexión. Mas no dejó de reiterar que los mexicanos, al sentirse "incapaces de conquistar Texas, para satisfacer sus pasiones vengativas..., estarian deseosos de verlo desolado y de nuevo en manos de los salvajes". ${ }^{12}$ Para eso, decia, se habian aliado con varias tribus hostiles. Aseguró que con su política de acoso continuo se proponía ganar tiempo para concentrar una fuerza capaz de invadir la rebelde provincia. Demandó que los Estados Unidos acatasen el Tratado de Amistad, Comercio y Navegación celebrado con México en 1831, y que valia para Texas mientras no se negociara uno nuevo. Debian tomar medidas adecuadas para evitar más migraciones indígenas hacia el suroeste y para obstaculizar la alianza entre los indios residentes en ambos paises.

El Departamento de Estado norteamericano respondió con energía: el tratado de 1831 no obligaba a sus firmantes a evitar las migraciones pacíficas, sino a mantener la tranquilidad entre los indígenas de la frontera y a impedir que atacasen a los ciudadanos de la nación contigua. Los Estados Unidos lo habian cumplido escrupulosamente. Empero, ofreció que el Departamento de Guerra trataría de persuadir a los indios de permanecer en paz en sus tierras y de evitar su empleo como mercenarios a sueldo de México, al igual que sus entradas ilegales a Texas.

El ascenso de John Tyler a la presidencia de los Estados Unidos en 1841 dio nuevas esperanzas a los interesados en la anexión texana, pues el nuevo presidente era un expansionista convencido. Sin embargo, no tardaron en sufrir una desilusión. La permanencia en el Departamento de Estado de Daniel Webster (poco afín a la idea), las tensiones con México y la oposición abolicionista a la extensión de la esclavitud no permitirian la incorporación inmediata.

Fue durante esta temporada cuando el gobierno de Texas, dirigido entonces por Samuel Houston, demandó la mediación norteamericana en su conflicto con México para conseguir la aceptación de la independencia, o una tregua que durase varios años. Era urgente, Santa Anna, otra vez en el poder, se manifestaba por la guerra. De nuevo se procuró la anexión, oferta que se mantuvo abierta hasta julio de 1843. Pero el gobierno de los Estados Unidos no expresó ningún interés, por lo cual, exasperado, y tal vez con el deseo de acicatearlo, Houston aprobó un armisticio con México propuesto por Francia y Gran Bretaña, según el cual aceptaba la soberanía mexicana sobre Texas. Así, según los diplomáti-

I: Anson Jones a Forsyth, Washington, 31 de diciembre de 1838, en ibidem. vol. 12. p. 179. 
cos europeos, se hacia factible negociar el reconocimiento de la autonomía. Cabe señalar que la mediación contó con el respaldo de Waddy Thompson, ministro de los Estados Unidos en México.

La correspondencia texana de estos meses utilizaba, de nueva cuenta, los sufrimientos de la lucha fronteriza y el temor a la reconquista como argumentos para lograr sus objetivos. Contrastaba la manera brutal de guerrear de los mexicanos con la conducta humana de los habitantes de Texas. Mas amenazaba con llevar el combate más allá del río Bravo, "contra un enemigo demasiado cobarde para llevar a cabo sus muchas y ruidosas amenazas y demasiado miserable para considerar las propuestas de paz"; la cansada población ya no queria "exponer a sus pueblos -sus altares e indefensas mujeres y niños- a las fuerzas de su ferocidad salvaje". "13

Los éxitos militares de los mexicanos en 1842 (se apoderaron de San Antonio Béjar en dos ocasiones) causaron gran preocupación entre los texanos. Presionaron otra vez al gobierno norteamericano para que lograse el reconocimiento de su independencia $u$ obligara al vecino mexicano a luchar de acuerdo con las reglas establecidas y aceptadas universalmente por las naciones civilizadas y cristianas. En dos cartas casi idénticas (una dirigida por el Departamento del Estado de Texas a Joseph Eve, representante de los Estados Unidos, y la otra por Isaac Van Zandt, el encargado texano de negocios en Washington, a Daniel Webster) acusaron a México de violar frecuente y abiertamente dichas reglas. ${ }^{14}$

Van Zandt llevó la cuestión del carácter de la guerra a la Casa Blanca al finalizar el año. El presidente Tyler le ofreció mediar ante el gobierno de México en la primera oportunidad. En efecto, un par de meses después, el ministro Waddy Thompson se entrevistó con el secretario de Relaciones Exteriores y le manifestó que si bien los Estados Unidos estaban dispuestos "a observar la más estricta neutralidad" mientras durase el conflicto entre sus dos vecinos, "sentian que era su deber reconvenir de la manera más respetuosa a ambos gobiernos contra las incursiones depredatorias que se estaban llevando a cabo y que en realidad no tenian un carácter bélico... [al igual que] exhortarlos al abandono de tal sistema. cuyas únicas consecuencias eran el sufrimiento y la desgracia individual". 15

Los diplomáticos de Texas se inquietaron seriamente cuando el gobierno norteamericano acusó a sus compatriotas de combatir también de una manera salvaje contra México. De inmediato trataron de justificarlos. Van Zandt explicó que no se trataba.más que de la reacción de un pueblo exasperado, que al contrario del mexicano. habia luchado siempre de una manera civilizada y con "gran humanidad hacia la gente común". Si bien reconocía irregularidades, éstas no habian contado con la aprobación del gobierno y se debian a la inmadurez de sus instituciones y al estado de guerra

1: James Reily a Daniel Webster. Washington, 11 de junio de 1842, en ibidem. vol. 12. p. 236-237.

${ }_{17}$ G. W. Terrell a Joseph Eve, Washington. Texas. 15 de octubre de 1842 e Isaac Van Zandt a Webster. Washington. 14 de diciembre de 1842, en ibidem, vol. 12 , p. $249-253$ y $256-259$.

Waddy Thompson a Webster. México. 14 de marzo de 1843, en Carlos Bosch Garcia. Documentos de la relacion de Mlevico con los Estados Linidos. México. Universidad Nacional Autónoma de México. 1983-1985. 4 vols., vol. 3. p. 574. 
en que vivía el país. ${ }^{16}$ Alarmado por la amenaza norteamericana de suspender su mediación, insistió en que era fundamental. Si Texas no lograba la paz y no se le reconocía el derecho de autodeterminación, no tendría más que "adoptar el principio de la venganza". 17

Por otra parte, Anson Jones, el secretario de Estado texano, aseguró al representante de los Estados Unidos que el presidente Houston se oponia también a la guerra depredatoria y que emplearía todos los medios a su alcance para detener cualquier incursión ilegal. $^{18}$

Poco comprendida en todo Texas, la reciente política norteamericana hacia la República de la Estrella Solitaria dio un giro favorable hacia los anexionistas en el verano de 1843 , con el nombramiento de Abel P. Upshur, expansionista resuelto, como secretario de Estado, con las medidas coactivas del presidente mexicano Antonio López de Santa Anna, que llevarian al ministro Thompson a retirar su apoyo a la mediación internacional, y con el creciente interés en Texas de los abolicionistas británicos, que causó grave preocupación a los esclavistas y a los defensores de la Doctrina Monroe.

En efecto, en el mes de septiembre, Upshur manifestó al ministro de Texas el interés de su país por la anexión. En octubre y noviembre reiteró su oferta. Pese a que en Texas los problemas internos. el temor a la renovación de las hostilidades mexicanas y los innumerables y múltiples lazos con los Estados Unidos hacian que la mayoria la favoreciera, un orgullo nacional incipiente y un sentimiento de inseguridad ante las propuestas norteamericanas propiciaron la oposición de unos cuantos, entre ellos el presidente Houston, quien respondió al gobierno de Washington que la mediación europea ofrecía más oportunidades de paz y que no podía comprometer sus buenas relaciones con Francia e Inglaterra apostando todo en favor de una propuesta de anexión que el Congreso norteamericano podia rechazar.

Durante estos meses, el ministro de Texas en los Estados Unidos se atrevió incluso a exigir explicaciones y a demandar una indemnización, tanto por el desarme a traición de una partida de texanos por una patrulla del ejército norteamericano, junto al rio Arkansas (en la frontera entre los dos paises), como por una carta hecha pública del general Edmund P. Gaines al general Zachary Taylor, en la que se aplaudía esta acción militar y se declaraba que en tanto no hubiese un tratado de límites el ejército estadunidense podia operar hasta el rio Bravo. ${ }^{19}$

Nada conforme con el rechazo de Texas, Upshur insistió de nuevo en la anexión a principios de 1844. Creía contar con el voto de las dos terceras partes del Senado de su país y, decidido a obtener su objetivo, no dejó de recurrir a las amenazas; si no se llegaba a un acuerdo. las fricciones podrían provocar una guerra. ${ }^{20} \mathrm{~A}$ la

i" Van Zandt a Webster. Washington, marzo de 1843, en Manning, op. cil., vol. 12, p. 275

Hidem. vol. 12. p. 282.

is Eve a Webster. Galveston. 8 de mayo de 1843, en ibidem, vol. 12, p. 289.

14) Abel P. Upshur a William S. Murphy. Washington, 16 de enero de 1844, en ihide'm. vol. 12. p. 63.

2" Van Zandt a Upshur. Washington. 10 de noviembre de 1843, en ibidem. vol. 12. p. 316 
par ofreció seguridades militares y navales a Van Zandt, aunque sólo de manera verbal.

Sin embargo, antes de que estas novedades llegaran a Texas, la presión interna obligaria a Houston a cambiar de actitud. Manifestó entonces al gobierno norteamericano su decisión de considerar la incorporación, mas demandó su protección en cuanto se firmase un tratado, es decir, barcos en el golfo de México y tropas en la frontera, pues en cuanto el vecino del sur supiera de las negociaciones con Washington reanudaria las hostilidades.

William S. Murphy, representante de los Estados Unidos en Texas, aseguró a los texanos que su país los apoyaría en cualquier circunstancia. $^{21}$ Sólo asi accedieron a negociar. Cabe señalar que Murphy fue desautorizado por sus superiores. Mientras Texas no fuese parte de los Estados Unidos, el presidente no podía, de acuerdo con la Constitución, ofrecer una garantía militar y naval, si bien aceptaba concentrar fuerzas en el golfo y el suroeste como medida de precaución.

La muerte accidental de Upshur no detuvo las negociaciones. Con el apoyo de John C. Calhoun, nuevo secretario de Estado, el 12 de abril de 1844 se firmó un tratado de anexión. Houston pareció satisfecho, tal vez porque México había aceptado extender el periodo de armisticio y porque Calhoun aseguró, aunque en forma verbal, la garantía militar.

Cuando el dividido Senado norteamericano objetó la anexión, el malestar texano fue considerable. Empero, no se hizo nada por evitar que en busca de una resolución conjunta, el presidente Tyler enviase el tratado al Congreso. Eso se debió, en buena medida, al temor de que México quisiera "o renovar el sistema de guerra depredatoria contra Texas, o hacer un intento formidable para su conquista..."22 y a la ubicación de navios y soldados de los Estados Unidos frente a las costas y las fronteras.

Los diplomáticos texanos no dejaron de insistir en la cuestión de la protección. Demandaron a Washington que diese los pasos necesarios para ayudar a su nación, en vista de que se había reanudado la situación tirante con México a raíz de los tratos de unión.

El triunfo de James K. Polk, que pedía la "reanexión" de Texas en el menor plazo posible, en las elecciones presidenciales de fin de año, fue interpretado por el presidente Tyler como una manifestación del deseo popular de expansión. En su último mensaje anual denunció a México por la guerra de desolación que llevaba a cabo en la frontera y urgió la incorporación texana. La Cámara de Representantes votó a favor en enero de 1845 y el Senado un mes después. El $1^{\circ}$ de marzo, Tyler firmó la resolución legislativa.

Las noticias llegaron a Texas a fines de mes. Bien acogidas por la opinión pública, que después de la elección de Polk había renacido en "el amor natural que une a un pueblo con su madre tierra", al entonces presidente Anson Jones, que personalmente se inclinaba por la garantía británica de la independencia y las fron-

"Murphy a Upshur, Washington, Texas, 15 de febrero de 1844 , en ibidem. vol. 12 , p. 330.

Ii- Jones a Tilghman A. Howard, Washington, Texas, 6 de agosto de 1844, en ibidem. vol. 12, p. 361 .

"3 Andrew J. Donelson a John C. Calhoun. Washington. Texas. 5 de diciembre de 1844, en ibidem. vol. 12, p. 379. 
teras, no le quedó otro remedio que convocar para su discusión al Congreso y al pueblo. El primero aprobó la medida el 18 de mayo, una convención popular el 4 de julio.

La probabilidad de la anexión despertó tal inquietud en el gobierno de Texas que no dudó en solicitar "en caso de emergencia anticipada, el paso de tropas de los Estados Unidos a través del territorio", hasta el rio Bravo, y en asegurar que sería "bienvenido y facilitado tanto por las autoridades constituidas como por el pueblo de su país". "Vale señalar que en realidad no tenían de qué preocuparse. Consumada la anexión, las tropas del general Zachary Taylor acampaban junto al rio Nueces. De ahí iniciarian la marcha sobre la República mexicana.

Utilizado en numerosas ocasiones por sus funcionarios, el tema de la reconquista por parte de México y de sus padecimientos por la guerra fronteriza sirvió a los texanos como un instrumento diplomático de peso esgrimido sobre los Estados Unidos. Jamás alcanzaron, sin embargo, la meta deseada. Si bien proporcionaron a las autoridades norteamericanas un lenguaje con el cual presionar a México, fueron los intereses estadunidenses los que en realidad determinaron el futuro de Texas. 